\title{
Crisis y reestructuración de los tejidos fabriles en espacios intraurbanos. El caso del barrio de San Isidro
}

\author{
Francisco del Castillo Garcia*
}

\section{RESUMEN}

Con este artículo se realiza un análisis de las últimas tendencias del tejido industrial de una zona intraurbana, el barrio de San Isidro, inserto en el distrito de Carabanchel. En el barrio se está produciendo una concentración y especialización de las actividades fabriles en la zona de Matilde Hernández-Pedro Diez.

Palabras clave: Industria intraurbana, Carabanchel, San Isidro, Concentración fabril, Especialización.

\section{SUMMARY}

In this article an analysis is done on the latest trends of the industry in the inter-city neighbourhood of San Isidro, in the Carabanchel district. In this neighbourhood there is a concentration and specialization of manufacturing activities occurring in the Matilde Hernández-Pedro Diez area.

Key words: Inter-city industry, Carabanchel, San Isidro, manufacturing concentration, specialization.

(*) Geógrafo. 


\section{CONSIDERACIONES PREVIAS}

El principal objeto de este trabajo, como su título indica es analizar la estructura y dinamismo del tejido fabril de uno de los siete barrios del distrito madrileño de Carabanchel (ver apéndice). Dado que también se querian conocer las pautas de localización de los establecimientos fabriles, su organización interna y las perspectivas de futuro, ha sido necesario efectuar una encuesta a una parte de las empresas ubicadas en el barrio. Así, se ha confeccionado un cuestionario amplio para realizar la encuesta, base fundamental del trabajo de campo, que se ha pasado a 31 establecimientos de diversas ramas fabriles y de diferente tamaño (según el empleo que ocupan). Por otra parte, para la evolución y las contextualizaciones a escala municipio y distrito se han utilizado además de fuentes bibliográficas, el Registro Industrial del MINER y los Directorios Industriales de la Comunidad de Madrid.

\section{INTRODUCCIÓN}

Por evidente, nadie cuestiona la importancia que la industria ha tenido no sólo en el crecimiento de las ciudades sino también en la vertebración del territorio.

A partir de la Revolución industrial las actividades fabriles han estado fuertemente relacionadas con la ciudad, y la etapa desarrollista de reconstrucción que siguió a la II Guerra Mundial consagró la afinidad de las actividades fabriles y los espacios urbanos.

Sin embargo a partir de la mitad de la década de los setenta y debido, sobre todo, al proceso de reestructuración productiva que siguió a la crisis, parece ser que empezaron a cuestionarse los beneficios de la localización industrial en las ciudades. De este modo determinadas sectores fabriles parecian buscar espacios más favorables (menor control sindical, menor precio del suelo, menores cargas tributarias, etc.) para ejercer sus actividades. Es decir, que el modelo basado en las ventajas que ofrecía la acumulación entraba en crisis y parecía perder relevancia en favor de otro más flexible favorecido por la segmentación de los procesos productivos.

$Y$ al cambio de modelo que daba un mayor protagonismo a otro tipo de espacios se han añadido diversas explicaciones merced a cuantiosos estudios de sociólogos, geógrafos, ingenieros, economistas, etc, sobre: industrialización endógena, industrialización rural, descentralización productiva, desindustrialización urbana, difusión industrial, etc. 
A todo ello, se le está uniendo en los últimos tiempos una creciente confusión entre el sector industrial y el de servicios, ya que la terciarización que se está dando en la economia también afecta al sector secundario. Esta terciarización hace que en las ciudades de países más desarrollados, el sector servicios tenga un peso económico muy superior al de la industria. A pesar de estos fenómenos la importancia de las actividades fabriles de las ciudades sigue siendo muy grande, y la pervivencia del atractivo urbano para determinados sectores se ha puesto de manifiesto en la corta etapa de bonanza que ha experimentado la economía mundial en la segunda mitad de la decada de los ochenta.

En el caso de Madrid, en la fase de desarrollo acumulativo la industria fue el sector con un mayor protagonismo. Desde el punto de vista espacial esta etapa consagró la localización fabril en la zona meridional del municipio madrileño, con notable presencia de la gran empresa y de la industria pesada y de automoción según muestran las cifras siguientes.

\section{ESTRUCTURA INDUSTRIAL POR DISTRITOS EN 1978}

\begin{tabular}{|c|c|c|c|c|c|}
\hline DISTRITO & ESTAB. & $\%$ & EMPLEO & $\%$ & $\begin{array}{l}\text { TAMAÑO } \\
\text { MEDIO }\end{array}$ \\
\hline 1. Centro................... & 865 & 11,2 & 6.130 & 3,4 & 7,1 \\
\hline 2. Arganzuela ............ & 297 & 3,8 & 27.456 & 15,2 & 92,4 \\
\hline 3. Retiro...................... & 202 & 2,6 & 4.997 & 2,8 & 24,7 \\
\hline 4. Salamanca.............. & 411 & 5,3 & 7.709 & 4,3 & 18,8 \\
\hline 5. Chamartin... & 330 & 4,3 & 11.490 & 6,4 & 34,8 \\
\hline 6. Tetuán ........... & 805 & 10,4 & 7.513 & 4,2 & 9,3 \\
\hline 7. Chamberí.............. & 283 & 3,7 & 3.243 & 1,8 & 11,5 \\
\hline 8. Fuencarral .............. & 208 & 2,7 & 5.723 & 3,2 & 27,5 \\
\hline 9. Moncloa ................ & 150 & 1,9 & 2.123 & 1.2 & 14,2 \\
\hline 10. Latina............... & 409 & 5,3 & 3.736 & 2,1 & 9,1 \\
\hline 11. Carabanchel... & 1.076 & 13,9 & 10.745 & 6,0 & 10,0 \\
\hline 12. Villaverde...... & 524 & 6,8 & 35.912 & 19,9 & 68,5 \\
\hline 13. Mediodia....... & 207 & 2,7 & 7.091 & 3,9 & 34,3 \\
\hline 14. Vallecas ................. & 629 & 8,1 & 4.578 & 2,5 & 7,3 \\
\hline 15. Moratalaz.............. & 107 & 1,4 & 3.649 & 2,0 & 34,1 \\
\hline 16. Ciudad Lineal......... & 715 & 9,3 & 9.073 & 5,0 & 12,7 \\
\hline 17. San Blas ................ & 354 & 4,6 & 25.368 & 14,1 & 71,7 \\
\hline 18. Hortaleza ... & 158 & 2,0 & 3.713 & 2,1 & 23,5 \\
\hline Total Madrid & 7.730 & 100 & 180.249 & 100 & 23,3 \\
\hline
\end{tabular}

Fuente: Censo Industrial del I.N.E. y elaboración propia. 
Los distritos meridionales acaparaban en 1978 casi la mitad (más del 47\%) del empleo fabril del municipio de Madrid.

No obstante si en el período desarrollista, como han señalado, diversos autores, la industria era la locomotora que tiraba de la economía, ahora es el sector servicios, que siempre ha sido importante (GARCIA DELGADO, J.L. 1990; MÉndez, R. 1986; SANZ, J.M. 1977; etc.) el que ha tomado el relevo. Sin embargo, se insiste en ello, la importancia de la industria urbana madrileña sigue siendo muy grande, baste señalar que en 1992, según el Directorio Industrial de la Comunidad de Madrid, el municipio tenía 9.901 establecimientos fabriles (52,4\% de la Comunidad), que ocupaban a 118.552 trabajadores $(44,8 \%$ de la Comunidad).

Por zonas geográficas la distribución de establecimientos y empleos en 1992, era como se detalla a continuación:

\begin{tabular}{|c|c|c|c|c|}
\hline ZONAS & ESTABTOS. & EMPLEO & TAMAÑO & ANTIGÜEDAD \\
\hline Centro-Oeste .............. & 3.858 & 34.846 & 9 & 20 \\
\hline Sur ............................ & 3.051 & 44.376 & 15 & 13 \\
\hline Norte-Este ................. & 2.992 & 39.330 & 13 & 13 \\
\hline Madrid capital .............. & 18.881 & 118.552 & 12 & 16 \\
\hline
\end{tabular}

Fuente: Directorio Industrial Comunidad de Madrid 1992

A pesar de haber sido la más perjudicada por la crisis, por el predominio de la gran empresa y la especialización en sectores maduros, la zona meridional sigue siendo la que tiene mayor protagonismo dentro del municipio. Acapara el $37,5 \%$ del empleo fabril y tiene el mayor tamaño por número de trabajadores. Este peso no sólo se debe a la pervivencia de ciertas actividades, sino también a la reconversión (con nuevas implantaciones) que se está dando de su tejido fabril, como demuestra una antigüedad de las empresas inferior a la media municipal.

\section{REESTRUCTURACIÓN PRODUCTIVA}

Como la crisis parece que supuso una ruptura del modelo de acumulación en las zonas metropolitanas, la mayoría de las grandes ciudades españolas sufrieron sus graves efectos (desindustrialización, cierres, paro, etc). 
Crisis y reestructuración de los tejidos fabriles en espacios intraurbanos...

Sin embargo, Madrid debido a la diversificación de su abanico fabril ha sido menos afectada por la crisis que otras zonas industriosas españolas.

$Y$ dentro de Madrid, a escala distrito, Carabanchel, según muestran las cifras siguientes, en contraste con los vecinos distritos meridionales (basados en la industria pesada) ha soportado mejor esta etapa recesiva según muestran las cifras siguientes.

\begin{tabular}{|c|c|c|c|c|c|c|}
\hline \multirow{2}{*}{ DISTRITO } & \multicolumn{2}{|c|}{1978} & \multicolumn{2}{|c|}{1987} & \multicolumn{2}{|c|}{ СТО. $\% 87 / 78$} \\
\hline & EST & EMPLEO & EST & EMPLEO & EST & EMPLEO \\
\hline CENTRO ......... & 865 & 6.138 & 1.000 & 5.797 & 15,6 & $-5,4$ \\
\hline ARGANZUELA. & 297 & 27.456 & 380 & 19.724 & 27,9 & $-28,2$ \\
\hline RETIRO.. & 202 & 4.997 & 276 & 4.370 & 36,6 & $-12,6$ \\
\hline SALAMANCA.. & 411 & 7.709 & 578 & 10.119 & 40,6 & 31,3 \\
\hline CHAMARTIN . & 330 & 11.490 & 408 & 7.592 & 23,6 & $-33,9$ \\
\hline TETUÁN ....... & 805 & 7.513 & 1.093 & 8.578 & 35,8 & 14,2 \\
\hline CHAMBERÍ ............... & 283 & 3.243 & 451 & 7.919 & 59,4 & 144,2 \\
\hline FUENCARRAL & 208 & 5.723 & 335 & 6.071 & 61,1 & 6,1 \\
\hline MONCLOA ....... & 150 & 2.123 & 232 & 3.513 & 54,7 & 65,5 \\
\hline LATINA .................... & 409 & 3.736 & 574 & 3.663 & 40,3 & $-2,0$ \\
\hline CARABANCHEL ....... & 1.076 & 10.745 & 1.210 & 13.394 & 12,5 & 24,7 \\
\hline VILLAVERDE ........... & 524 & 35.912 & 689 & 19.865 & 31,5 & $-44,7$ \\
\hline MEDIODÍA................ & 207 & 7.091 & 320 & 7.708 & 54,6 & 8,7 \\
\hline VALLECAS $\ldots \ldots \ldots \ldots \ldots$ & 629 & 4.578 & 651 & 3.387 & 3,5 & $-26,0$ \\
\hline MORATALAZ.. & 107 & 3.649 & 170 & 2.959 & 58,9 & $-18,9$ \\
\hline CIUDAD LINEAL ...... & 715 & 9.073 & 791 & 12.266 & 10,6 & $-35,2$ \\
\hline SAN BLAS ................ & 354 & 25.368 & 564 & 19.939 & 59,3 & $-21,4$ \\
\hline HORTALEZA ............ & 158 & 3.713 & 311 & 4.513 & 96,9 & 21,6 \\
\hline MADRID ..... & 7.730 & 180.257 & 10.033 & 161.377 & 29,8 & $-10,5$ \\
\hline
\end{tabular}

Fuente: Censo Industrial INE (1978) Directorio Industrial de la Comunidad de Madrid (1987) y elaboración propia.

Ello se debe, fundamentalmente, a su perfil empresarial de pequeña empresa (más flexible), y a su diversificación productiva con poca especialización en sectores básicos.

Dentro de la zona sur, Carabanchel es el que cuenta con mayor número de establecimientos, aunque no es el distrito que ocupa más empleo, debido al citado predominio de la pequeña y mediana empresa. Por 
otra parte, a la luz de las cifras se aprecia que frente a la tendencia general de disminución de empleo e incremento del número de establecimientos, y, por lo tanto, aumento del tamaño de las empresas, Carabanchel acapara más empleo fabril al final del período.

Desde el punto de vista de las ramas de actividad la evolución de la estructura fabril en este período se puede intuir por los datos que a continuación se detallan.

\begin{tabular}{|c|c|c|c|c|c|c|c|c|c|c|c|}
\hline \multirow{3}{*}{ SECTORES } & \multicolumn{5}{|c|}{1978} & \multicolumn{5}{|c|}{1987} & \multirow{3}{*}{$\begin{array}{l}\text { VARIAC } \% \\
\text { EMP. } 78.87\end{array}$} \\
\hline & & & & & EMPLEO & & & & & EMPLEO & \\
\hline & EST. & $\%$ & EMPLEO & $\%$ & MEDIO & EST. & $\%$ & EMPLEO & $\%$ & MEDIO & \\
\hline M. no metálicos & 33 & 3,1 & 347 & 3,2 & 10,5 & 41 & 3,4 & 166 & 1,2 & 1,2 & $+52,2$ \\
\hline Metál. básicas & 2 & 0,2 & 22 & 0,2 & 11,0 & 4 & 0,3 & 31 & 0,2 & 7,8 & $+40,9$ \\
\hline T. Metálicos & 224 & 20,8 & 1.302 & 12,1 & 5,8 & 212 & 17,5 & 1.671 & 12,5 & 7,9 & $+28,3$ \\
\hline M. M. Transporte & 82 & 7,6 & 1.501 & 14,0 & 6,7 & 113 & 9,3 & 5.765 & 43,0 & 51,0 & $+384,1$ \\
\hline Alimentación & 89 & 8,3 & 854 & 8,0 & 9,6 & 98 & 8,1 & 582 & 4,4 & 5,9 & $-31,9$ \\
\hline Textil, Cuero & 143 & 13,3 & 2.664 & 24,8 & 18,6 & 185 & 15,3 & 1.735 & 13,0 & 9,4 & $-34,9$ \\
\hline Madera y corcho & 281 & 26,1 & 1.165 & 10,8 & 4,1 & 232 & 19,2 & 682 & 5,1 & 2,9 & $-41,5$ \\
\hline P. y A. Gráficas & 133 & 12,4 & 1.646 & 15,3 & 12,4 & 215 & 17,8 & 2.060 & 15,4 & 9,6 & $+25,2$ \\
\hline Químicas & 54 & 5,0 & 943 & 8,8 & 17,5 & 57 & 4,7 & 372 & 2,8 & 6,5 & $-60,6$ \\
\hline Otras industrias & 35 & 3,2 & 301 & 2,8 & 8,6 & 53 & 4,4 & 330 & 2,4 & 6,2 & $+9,6$ \\
\hline TOTAL & 1.076 & 100 & 10.745 & 100 & 10,0 & 1.210 & 100 & 13.394 & 100 & 11,1 & $+24,7$ \\
\hline
\end{tabular}

Fuente: Censo Industrial del I.N.E. 1978 y Directorio Industrial de la C.A.M. de 1987.

\subsection{Localización de las actividades fabriles}

Según el Directorio Industrial de la Comunidad de Madrid en el período 1985-1987, todos los barrios del distrito (a excepción de Abrantes) han tenido un dinamismo industrial superior a la media del municipio, utilizando como indicador las nuevas instalaciones fabriles.

Sin embargo, entre ellos se dan notables diferencias en función de su localización (centralidad, cercanía a redes de transporte,...), normativa legal, etc.

Una prueba de ello se aprecia por los datos que a continuación se ofrecen en base al Directorio de la Comunidad de Madrid. 
Crisis y reestructuración de los tejidos fabriles en espacios intraurbanos...

CINCO BARRIOS CON MAYOR VOLUMEN DE EMPLEO EN NUEVAS IMPLANTACIONES INDUSTRIALES DESDE 1985 HASTA 1987

\begin{tabular}{lccc}
\hline \multicolumn{1}{c}{ BARRIO } & DISTRITO & ESTAB. & EMPLEOS \\
\hline Valverde ....................... & Fuencarral & 24 & 913 \\
Simancas ...................... & San Blas & 76 & 877 \\
Legazpi ....................... & Arganzuela & 14 & 867 \\
San Isidro ..................... & Carabanchel & 98 & 726 \\
Buenavista ..................... & Carabanchel & 23 & 547 \\
\hline TOTAL MADRID ............ & & 638 & 8.174 \\
\hline
\end{tabular}

Fuente: Estudio sobre la situación actual y previsible evolución del sector industrial en el municipio de Madrid. Ayuntamiento de Madrid.

En el citado período dos barrios de Carabanchel están situados entre los cinco primeros por el empleo ocupado por las nuevas implantaciones. Además, San Isidro ha sido el barrio de Madrid que ha tenido un mayor volumen de nuevas implantaciones aunque por el empleo ocupado se sitúa en el cuarto lugar con una media de tan sólo 7,4 trabajadores por establecimiento. Por el contrario, el perfil de las empresas de Buenavista es diferente al del distrito, ya que sus 23 establecimientos acaparan 547 trabajadores con un tamaño medio de 23,8 empleos.

Estos datos corroboran que si en la etapa de crisis ya se produjo una cierta huida hacia las zonas más exteriores del distrito, en el período de bonanza se va a continuar esa tendencia con una marcada segregación espacial desde el punto de vista fabril. Las empresas van a ubicarse preferentemente en los barrios de San Isidro y de Buenavista. En el primero en la zona de Matilde Hernández, y en el segundo en el Polígono de Aguacate-Tamames.

En la década de los setenta era ya evidente que en el distrito existía una marcada polarización espacial de las empresas fabriles y San Isidro era el barrio que tenía una mayor actividad industrial debido, sobre todo, a la zona de Matilde Hernández-Pedro Díez (Del Castillo, F. 1992). Pero durante la crisis es cuando se va a producir una mayor concentración en la citada área, debido, tanto a la atracción que ejercía con su oferta de suelo para uso fabril, como a la paulatina desaparición de la pequeña industria dispersa intraurbana que convivía con el uso residencial y que va despoblando otras áreas de actividad industrial.

Por otra parte, como se ha podido constatar por la encuesta realizada, en esta etapa las empresas que lograron sobrevivir y que tenían el local 
en régimen de alquiler ya no pueden soportar los elevados costes del suelo que ocupaban y se ubican en las zonas legalmente segregadas para las actividades industriales (con suelo más barato).

También hay que añadir la presión que ejerce sobre el precio del suelo el uso residencial y terciario. Todo ello, expulsa a las empresas propietarias de naves hacia otras zonas menos centrales al tiempo que les proporciona una renta diferencial imprescindible para efectuar una capitalización que les permita adaptarse a las nuevas condiciones que impone la crisis.

De este modo, en el año 1987 San Isidro acaparaba más de la quinta parte del empleo fabril del distrito y Buenavista iba, de forma lenta, adquiriendo un mayor protagonismo fabril a medida que se iba colmatando la zona industrial de Aguacate-Tamames, sobre todo, cuando se vió favorecida por la mejora en los accesos (como la realización de la M-40 y la reciente reordenación de la Avda. de los Poblados). Pero esta concentración también se observa si se hace el análisis a menor escala dentro de cada barrio. En este sentido es interesante destacar que dentro del barrio de San Isidro tan sólo las cinco calles que a continuación se detallan acaparan 60 establecimientos de las nuevas implantaciones fabriles.

\begin{tabular}{lc}
\hline CALLE & № ESTABTOS. \\
\hline Avda Pedro Díez & 18 \\
Matilde Hernández & 13 \\
Nicolás Morales & 12 \\
Santiago Estévez & 12 \\
Cañete & 5 \\
\hline
\end{tabular}

Fuente: Directorio Industrial C.A.M.

Y además, entre las quince calles con mayor número de implantaciones de Madrid en ese periodo, figuraban siete de Carabanchel. Las citadas cuatro primeras de San Isidro y las tres restantes de otros barrios: Antoñita Jiménez (6) de Opañel, Conde de Vistahermosa (6) de Comillas y Julia Nebot (6) de Vista Alegre.

Por todo ello, se puede plantear que se está dando una notable segregación del espacio con una creciente concentración en determinadas áreas ( $y$ en determinadas calles) de las actividades fabriles en el distrito en los últimos tiempos. 
Al final del periodo de bonanza económica, en el año 1990 los 1.174 establecimientos fabriles de Carabanchel se repartían por sus barrios según se detalla a continuación.

\begin{tabular}{lrrrrr}
\hline \multirow{2}{*}{ BARRIOS } & \multicolumn{2}{c}{ ESTABLTOS. } & \multicolumn{2}{c}{ EMPLEOS } & TAMAÑO EST. \\
\cline { 2 - 6 } & \multicolumn{1}{c}{$N^{\circ}$} & $\%$ & \multicolumn{1}{c}{$N^{\circ}$} & $\%$ & EMP. MEDIO \\
\hline 1. Comillas & 121 & 10,3 & 635 & 7,1 & 5,2 \\
2. Opañel & 184 & 15,7 & 1.158 & 13,0 & 6,3 \\
3. San Isidro & 358 & 30,5 & 3.786 & 42,6 & 10,6 \\
4. Vista Alegre & 207 & 17,6 & 901 & 10,2 & 4,4 \\
5. Puerta Bonita & 135 & 11,5 & 740 & 8,3 & 5,6 \\
6. Buenavista & 98 & 8,3 & 1.282 & 14,4 & 13,2 \\
7. Abrantes & 71 & 6,1 & 390 & 4,4 & 5,5 \\
Carabanchel & 1.174 & 100 & 8.892 & 100 & 7,6 \\
\hline
\end{tabular}

Fuente: Directorio Industrial de la C. A. de Madrid 1990 y elaboración propia.

San Isidro, se configura claramente como el barrio más importante desde el punto de vista fabril. Con el $30 \%$ de empresas acapara el $42,6 \%$ del empleo industrial de Carabanchel debido a que el tamaño medio (en trabajadores) de sus establecimientos, aun siendo pequeño en relación a Madrid, es superior al de la media del distrito.

Buenavista es el segundo barrio en importancia por volumen de empleo ocupado, a distancia del primero, pero con una tendencia creciente al contrario que Opañel, que, de igual forma que Comillas, está viendo descender sus efectivos fabriles por su situación de mayor centralidad en el municipio madrileño. Sin embargo, todavía quedan instalaciones industriales enquistadas en el tejido urbano residencial.

Vista Alegre también está perdiendo protagonismo fabril en favor de las actividades terciarias, ya que este barrio es con diferencia el más importante de Carabanchel desde el punto de vista comercial.

Abrantes va aumentando los efectivos fabriles de forma lenta en torno a las proximidades del Parque Sur al borde de la Avda. de los Poblados y de la Vía Lusitana. En esta zona se van instalando industrias pero tienen una mayor presencia las empresas comerciales concesionarias de automóviles. 


\section{LA CRISIS DE LOS NOVENTA}

\subsection{Introducción}

Si a finales de la década de los ochenta ya se produjo un enfríamiento de la economía, en los noventa se ha dado una notable caída de las actividades industriales en nuestro país, y a los efectos de la crisis de tipo coyuntural en los ámbitos fabriles se le unen otros estructurales, debidos tanto a la terciarización como a la mundialización de la economía.

\subsection{Contexto madrileño}

En Madrid, a escala distrito las cifras arrojan la siguiente situación.

\begin{tabular}{|c|c|c|c|c|c|c|}
\hline \multirow{2}{*}{ DISTRITOS } & \multicolumn{2}{|c|}{1990} & \multicolumn{2}{|c|}{1992} & \multicolumn{2}{|c|}{ VAR $(\%) 90 / 92$} \\
\hline & EST. & EMPLEO & EST. & EMPLEO & EST. & EMPLEO \\
\hline Centro & 1.047 & 6.175 & 978 & 4.619 & $-6,6$ & $-25,2$ \\
\hline Arganzuela & 455 & 16.122 & 435 & 11.446 & $-4,6$ & $-29,0$ \\
\hline Retiro & 243 & 3.198 & 215 & 2.365 & $-11,5$ & $-26,0$ \\
\hline Salamanca & 614 & 11.190 & 572 & 7.155 & $-6,8$ & $-37,0$ \\
\hline Chamartín & 440 & 11.810 & 385 & 8.088 & $-12,5$ & $-31,5$ \\
\hline Tetuán & 1.127 & 9.414 & 1.064 & 6.857 & $-5,6$ & $-27,2$ \\
\hline Chamberí & 464 & 6.304 & 420 & 2.954 & $-9,5$ & $-53,1$ \\
\hline Fuencarral & 328 & 4.374 & 314 & 3.960 & $-4,3$ & $-9,1$ \\
\hline Moncloa & 242 & 3.402 & 221 & 2.793 & $-8,7$ & $-17,9$ \\
\hline Latina & 628 & 2.142 & 609 & 2.979 & $-3,1$ & $+39,1$ \\
\hline Carabanchel & 1.174 & 8.892 & 1.126 & 7.980 & $-4,1$ & $-10,3$ \\
\hline Usera & 526 & 7.945 & 517 & 7.002 & $-1,8$ & $-6,6$ \\
\hline Pte. Vallecas & 693 & 3.725 & 697 & 3.403 & $+0,5$ & $-8,6$ \\
\hline Moratalaz & 57 & 233 & 60 & 236 & $+5,3$ & $+1,3$ \\
\hline Ciudad Lineal & 777 & 7.105 & 733 & 4.034 & $-5,7$ & $-43,3$ \\
\hline Hortaleza & 282 & 4.943 & 272 & 2.858 & $-3,5$ & $-42,2$ \\
\hline Villaverde & 369 & 19.016 & 359 & 14.948 & $-2,7$ & $-21,4$ \\
\hline Villa Vallecas & 148 & 2.060 & 172 & 2.394 & $+16,2$ & $+16,2$ \\
\hline Vicálvaro & 137 & 2.704 & 127 & 2.299 & $-7,3$ & $-15,0$ \\
\hline San Blas & 602 & 19.668 & 552 & 17.787 & $-8,3$ & $-9,6$ \\
\hline Barajas & 65 & 3.191 & 61 & 2.306 & $-6,2$ & $-27,7$ \\
\hline Madrid & 10.428 & 153.211 & 9.889 & 118.459 & $-5,2$ & $-22,7$ \\
\hline
\end{tabular}

Fuente: Directorios C.A.M. 1990, 1992 y elaboración propia. 
Por los datos anteriores se evidencia que el tejido industrial de Carabanchel ha sido menos afectado, en términos cuantitativos, por la recesión, pues ha tenido una caída del empleo inferior a la media del municipio y el descenso en el número de establecimientos también ha sido menor en términos relativos.

\subsection{Estructura sectorial}

En cuanto a su estructura por ramas de actividad, se constata por las cifras siguientes que el perfil sectorial del distrito continúa casi prácticamente inalterable a lo largo del tiempo.

ESTRUCTURA INDUSTRIAL DE CARABANCHEL EN 1992

\begin{tabular}{lrrrrr}
\hline \multirow{2}{*}{ SECTORES } & \multicolumn{2}{c}{ ESTABLEC. } & \multicolumn{2}{c}{ EMPLEO } & \\
\cline { 2 - 5 } & \multicolumn{1}{c}{$N^{\circ}$} & $\%$ & \multicolumn{1}{c}{$^{\circ}$} & $\%$ & $\begin{array}{c}\text { EMP. MEDIO } \\
\text { EMP/ESTAB. }\end{array}$ \\
\hline Metal. básicas & 7 & 0,5 & 45 & 0,6 & 6,4 \\
No metálicos & 38 & 3,4 & 205 & 2,6 & 5,4 \\
Química & 18 & 1,6 & 113 & 1,4 & 6,3 \\
Const. metál. & 117 & 10,4 & 398 & 5,0 & 3,4 \\
Artic. metál. & 57 & 5,1 & 375 & 4,7 & 6,6 \\
Maq. industrial & 32 & 2,8 & 309 & 3,9 & 9,7 \\
M.eltco electrónico & 75 & 6,7 & 605 & 7,5 & 8,1 \\
Mat. transporte & 9 & 0,8 & 250 & 3,1 & 27,8 \\
Alimentación & 88 & 7,8 & 478 & 6,0 & 5,4 \\
Textil y calzado & 189 & 16,8 & 1.726 & 21,6 & 9,1 \\
Papel, imprentas & 209 & 18,6 & 2.327 & 29,2 & 11,1 \\
Madera y mueble & 221 & 19,6 & 667 & 8,4 & 3,0 \\
Otras industrias & 66 & 5,9 & 482 & 6,0 & 7,3 \\
Total & 1.126 & 100 & 7.980 & 100 & 7,1 \\
\hline
\end{tabular}

Fuente: Directorio Industrial Comunidad de Madrid de 1992 y elaboración propia.

Así, el mayor número de establecimientos (y también de empleo) lo siguen acaparando las ramas de actividad tradicionales, entendiendo como tales: Papel y artes gráficas; Textil, confección, cuero y calzado; Madera y muebles; Alimentación, etc. Estas actividades, salvo excepciones, están 
muy vinculadas con el consumo del enorme mercado del área metropolitana madrileña.

\subsection{Localización de la industria}

Ya se ha comentado repetidas veces que la dispersión por todo el distrito es una de las características de la industria de Carabanchel, sin embargo, existe una segregación a escala barrio que ya se puso de manifiesto al final del proceso de implantación y que continúa según se observa por los datos siguientes.

\begin{tabular}{lrrrrr}
\hline \multirow{2}{*}{ SECtores } & \multicolumn{2}{c}{ ESTABLtOS. } & \multicolumn{2}{c}{ EMPLEOS } & TAMAÑo EST. \\
\cline { 2 - 6 } & \multicolumn{1}{c}{$\mathrm{N}^{0}$} & $\%$ & $\mathrm{~N} N$ & $\%$ & EMP. MEDIO \\
\hline 1. Comillas & 111 & 9,9 & 584 & 7,3 & 5,3 \\
2. Opañel & 177 & 15,7 & 1.049 & 13,2 & 5,9 \\
3. San Isidro & 340 & 30,2 & 3.577 & 44,8 & 10,5 \\
4. Vista Alegre & 204 & 18,1 & 887 & 11,1 & 4,3 \\
5. Puerta Bonita & 130 & 11,5 & 709 & 8,9 & 5,5 \\
6. Buenavista & 99 & 8,8 & 819 & 10,3 & 8,3 \\
7. Abrantes & 65 & 5,8 & 355 & 4,4 & 5,5 \\
Carabanchel & 1.126 & 100 & 7.980 & 100 & 7,6 \\
\hline
\end{tabular}

Fuente: Directorio Industrial de la C. A. de Madrid 1992 y elaboración propia.

Sigue destacando la hegemonía fabril de San Isidro por el número de establecimientos que suponen algo más del $30 \%$ del total y, sobre todo, por el volumen de empleo que ocupa nada menos que un $44,8 \%$ de los trabajadores industriales del distrito. Es decir, que tiene más del triple de trabajadores que Opañel, distrito que le sigue en orden de importancia fabril por volumen de empleo.

Por otra parte, San Isidro se aparta del perfil empresarial del resto del distrito en cuanto al tamaño de sus empresas ya que su empleo es muy superior al de los restantes barrios a excepción de Buenavista. 
Crisis y reestructuración de los tejidos fabriles en espacios intraurbanos...

\section{EVOLUCIÓN EN EL BIENIO DEL VOLUMEN DE EMPLEOS Y DEL NÚMERO DE EMPRESAS}

\begin{tabular}{lrrrrrrr}
\hline \multirow{2}{*}{ BARRIOS } & \multicolumn{2}{c}{ ESTABLTOS. } & \multicolumn{2}{c}{ EMPLEOS } & \multicolumn{2}{c}{ EVOLUCIÓN } \\
\cline { 2 - 7 } & 1990 & 1992 & 1990 & 1992 & \multicolumn{1}{c}{ EST. } & EMP. \\
\hline 1. Comillas & 121 & 111 & 635 & 584 & $-8,3$ & $-8,0$ \\
2. Opañel & 184 & 177 & 1.158 & 1.049 & $-3,8$ & $-9,4$ \\
3. San Isidro & 358 & 340 & 3.786 & 3.577 & $-5,0$ & $-5,5$ \\
4. Vista Alegre & 207 & 204 & 901 & 887 & $-1,4$ & $-1,5$ \\
5. Puerta Bonita & 135 & 130 & 740 & 709 & $-3,7$ & $-4,2$ \\
6. Buenavista & 98 & 99 & 1.282 & 819 & $+1,0$ & $-36,1$ \\
7. Abrantes & 71 & 65 & 390 & 355 & $-8,5$ & $-9,9$ \\
Carabanchel & 1.174 & 1.126 & 8.892 & 7.980 & $-4,1$ & $-10,3$ \\
\hline
\end{tabular}

Fuente: Directorios Industriales de la C. A. de Madrid 1990, 1992 y elaboración propia.

A excepción de Buenavista (con una empresa más que en 1990) en todos los barrios se ha producido una pérdida pequeña (saldo neto) de establecimientos fabriles. San Isidro es el barrio que ha experimentado un mayor descenso con 209 establecimientos menos que en 1990. Pero en términos relativos los más perjudicados por los cierres o traslados han sido Comillas y Abrantes.

\section{EVOLUCIÓN RECIENTE DEL TEJIDO FABRIL DE SAN ISIDRO}

\subsection{Generalidades}

Debido a la ya contrastada importancia industrial de San Isidro, y dentro del barrio a la zona de Matilde Hernádez-Pedro Díez, se le va a dedicar un epigrafe especial a esta interesante aglomeración de empresas industriales.

San Isidro junto con Comillas (ver apéndice) forma el borde septentrional de Carabanchel que limita con el sur del distrito de Arganzuela. Cuenta con dos tipos de industrias en relación a su localización. Por un lado, la dispersa que englobaría las dos categorías de Pred, "ubícuas" y de "mercado local» (CARTER, H. 1983) y la otra concentrada configurando una especie de complejo industrial (CHARDONNET, J. 1953). El primero de los tipos, 
como es bien conocido, se compone de numerosas industrias muy esparcidas aunque tiene algunos focos aglutinantes en las calles de Paulina Odiaga e Isabel Ana en la mitad septentrional del barrio y en los bordes al norte del complejo industrial en un espacio sin solución de continuidad del mismo. El segundo es un enclave industrial que data de los inicios fabriles del distrito y que tiene un perfil empresarial marcadamente distinto al resto del barrio y del distrito.

\subsection{Evolución reciente}

En San Isidro, como en los restantes barrios del distrito también se han perdido efectivos fabriles en los últimos tiempos. Sin embargo, a pesar de esta disminución del empleo ha ido ganando cada vez más importancia en términos relativos a escala distrito.

\begin{tabular}{ccccccccc}
\hline \multicolumn{2}{c}{ ESTABLTOS } & \multicolumn{2}{c}{ EMPLEOS } & \multicolumn{2}{c}{ EVOLUCIÓN(\%) } & \multicolumn{2}{c}{ TAMAÑO } \\
\hline 1990 & 1992 & 1990 & 1992 & EST. & EMP. & 1990 & 1992 \\
\hline 358 & 340 & 3.786 & 3.577 & $-5,0$ & $-5,5$ & 10,6 & 10,5 \\
\hline
\end{tabular}

Fuente: Directorios Industriales C. Madrid 1990 y 1992 y elaboración propia.

En este bienio se ha dado una leve contracción del tejido industrial con una reducción de un $5 \%$ del número de establecimientos y una proporción similar pero algo superior $(5,5 \%)$ del volumen de empleo acogido y una permanencia del tamaño medio de las empresas, por encima que el conjunto de Carabanchel.

\subsection{Estructura sectorial}

En San Isidro aumenta de forma notable, con respecto a los restantes barrios del distrito, el abanico de actividades fabriles (ver epígrafe), sin embargo ello no quiere decir que no exista una marcada especialización en este barrio. En efecto, existe una fuerte concentración por ramas de actividad, ya que dos sectores ocupan, con el $46 \%$ del total de establecimientos fabriles, más del $60 \%$ del empleo de San Isidro. Además, el sector mayoritario, con un empleo medio de 14,8 trabajadores, llega incluso a sobrepasar el $40 \%$ de los puestos de trabajo. 
Crisis y reestructuración de los tejidos fabriles en espacios intraurbanos...

\begin{tabular}{|c|c|c|c|c|c|c|}
\hline \multirow{2}{*}{ SECTORES } & \multicolumn{2}{|c|}{ ESTAB. } & \multicolumn{2}{|c|}{ EMPLEO } & \multirow{2}{*}{$\begin{array}{l}\text { TAMAÑO } \\
\text { EMP/EST. }\end{array}$} & \multirow{2}{*}{$\begin{array}{r}\text { COEF. ESF } \\
\text { DISTRITO } \\
\text { (EMPLEO) }\end{array}$} \\
\hline & № & $\%$ & № & $\%$ & & \\
\hline Metálicas básicas & 4 & 1,2 & 30 & 0,8 & 7,5 & 1,3 \\
\hline I. no metál. & 11 & 3,2 & 106 & 3,0 & 9,6 & 1,2 \\
\hline Industria química & 9 & 2,6 & 58 & 1,6 & 6,4 & 1,1 \\
\hline Const. metálicas & 34 & 10,0 & 155 & 4,3 & 4,6 & 0,9 \\
\hline Artículos metálicos & 22 & 6,5 & 117 & 3,3 & 5,3 & 0,7 \\
\hline Maquinaria industrial & 8 & 2,3 & 119 & 3,3 & 14,9 & 0,8 \\
\hline Mat. eltco y eltrónico & 16 & 4,7 & 233 & 6,5 & 14,6 & 0,9 \\
\hline Material transporte & 7 & 2,1 & 244 & 6,8 & 34,9 & 2,2 \\
\hline Alimentación & 9 & 2,6 & 54 & 1,5 & 6,0 & 0,3 \\
\hline Textil, cuero, czdo. & 57 & 16,8 & 701 & 19,6 & 12,3 & 0,9 \\
\hline Papel, imprentas & 98 & 28,8 & 1.454 & 40,7 & 14,8 & 1,4 \\
\hline Madera y muebles & 41 & 12,1 & 100 & 2,8 & 2,4 & 0,3 \\
\hline Otras industrias & 24 & 7,1 & 206 & 5,8 & 8,6 & 1,0 \\
\hline Total San Isidro & 340 & 100 & 3.577 & 100 & 10.5 & \\
\hline
\end{tabular}

Fuente: Directorio Industrial C. Madrid 1992 y elaboración propia

A la luz de las cifras, la mayor especialización de San Isidro en relación a Carabanchel se da en Material de transporte, que tiene un coeficiente de 2,2. Esta actividad fabril ocupa a 244 trabajadores de los 250 del distrito, es decir prácticamente la totalidad del empleo $(97,6 \%)$.

No obstante, es evidente que el sector más importante es Papel, imprentas y edición que ocupaba en 1992 a 1.454 trabajadores en sus 98 establecimientos, localizados sobre todo en la zona industrial Matilde Hernández-Pedro Díez. En esta rama, la aportación principal con enorme diferencia la constituyen las distintas actividades de las imprentas, subrama que está representada por 92 empresas y que acapara a 1.338 trabajadores.

Textil, confección, cuero y calzados es el segundo sector en volumen de empleo y tiene la siguiente desagregación:

\begin{tabular}{lccc}
\hline SUBRAMA & ESTAB. & EMPLEOS & TAMAÑO \\
\hline Textil & 14 & 149 & 10,6 \\
Confección & 35 & 468 & 13,4 \\
Cuero y calzado & 8 & 84 & 10,5 \\
Total & 57 & 701 & 12,3 \\
\hline
\end{tabular}

Fuente: Directorio Industrial C. Madrid 1992. 
No es necesario insistir en la preeminencia de la confección de prendas de vestir que es otra de las peculiares actividades de la zona de Matilde Hernández y que suele localizar sus mayores empresas, algunas de ámbito nacional por el alcance de sus productos, en la calle de Pedro Díez.

Por el contrario tienen una pequeña representación en el total del empleo $(\mathrm{Ce}: 0,3)$ Alimentación, y también una actividad muy extendida por todo el distrito y bastante tradicional en él como Madera y muebles a pesar de que como es habitual tiene una importante número de establecimientos, situándose con 41 en tercer lugar por empresas del barrio.

\subsection{Tamaño empresarial}

El empleo medio de San isidro se aparta del muy reducido tamaño que caracteriza el perfil del distrito ya que llega a 10,5 trabajadores por empresa.

Por actividades, el mayor tamaño lo ostenta material de transporte con 34,9 empleos, seguido de maquinaria industrial con 14,9 empleos y otros tres entre los que se encuentran los que tiene una mayor implantación de empleo Papel, imprentas y edición con 14,8 trabajadores y Textil, confección, cuero y calzado con 12,3.

Entre estos últimos se sitúa material eléctrico con 14,6 empleos por establecimiento.

A continuación, se ofrece la evolución de las empresas por nivel de empleo.

\begin{tabular}{rrrrr}
\hline \multirow{2}{*}{$\begin{array}{c}\text { TAMAÑO } \\
\text { (NIVEL EMPLEO) }\end{array}$} & \multicolumn{3}{c}{1990} & \multicolumn{2}{c}{1992} \\
\cline { 2 - 5 } & EST. & EMPLEO & EST. & EMPLEO \\
\hline $1-19$ & 314 & 1.961 & 295 & 1.827 \\
$20-49$ & 34 & 1.007 & 38 & 1.168 \\
$50-100$ & 8 & 536 & 5 & 309 \\
$100-499$ & 2 & 282 & 2 & 273 \\
\hline
\end{tabular}

Fuente: Directorios C. Madrid y elaboración propia.

Por no insistir más, merced al nivel de empleo se puede observar que las empresas de menos de 20 trabajadores, que acaparaban la mayor parte del empleo en los anteriores distritos en este caso solamente llegan a suponer algo más de la mitad del mismo $(51,1 \%)$. Por el otro lado, las 
empresas con más de 50 empleos alcanzan el $16,3 \%$ del total de trabajadores.

\subsection{Antigüedad de las empresas}

La antigüedad de las empresas es un dato de notable importancia pues permite valorar no sólo la consolidación de los establecimientos a lo largo del tiempo, sino también el dinamismo del tejido fabril en épocas recientes.

La antigüedad media de San Isidro es de 14 años, pero dado que esta cifra no aporta mucho, es más interesante estudiar la segregación de las empresas de las que se tiene constancia del inicio de su actividad por tramos de edades.

\begin{tabular}{lrrrrr}
\hline \multirow{2}{*}{$\begin{array}{r}\text { INICIO DE } \\
\text { ACTIVIDAD }\end{array}$} & \multicolumn{2}{c}{ ESTAB. } & \multicolumn{2}{c}{ EMPLEO } & $\begin{array}{c}\text { TAMAÑO } \\
\text { EST/EMP. }\end{array}$ \\
\cline { 2 - 5 } Antes 1941 & 3 & 1,0 & 11 & 0,4 & 3,7 \\
$1941-1960$ & 27 & 9,3 & 312 & 10,8 & 11,6 \\
$1961-1970$ & 31 & 10,7 & 300 & 10,4 & 9,7 \\
$1971-1980$ & 69 & 23,8 & 840 & 29,0 & 12,2 \\
$1981-1985$ & 67 & 23,1 & 634 & 21,9 & 9,5 \\
$1986-1991$ & 93 & 32,1 & 794 & 27,5 & 8,5 \\
Total & 290 & 100 & 2.891 & 100 & 10,0 \\
\hline
\end{tabular}

Fuente: Directorio Industrial C. Madrid 1992 y elaboración propia.

Por la información obtenida de la encuesta y del Directorio, de las empresas anteriores a la crisis permanecen en èl tejido industrial del barrio casi el $35 \%$ del total, mientras que las recientes llegan a un $27,5 \%$. Es decir, que a pesar de subsistir un importante contingente de empresas antiguas, dada la tradición fabril del barrio, el alto dinamismo de la zona ha producido un notable rejuvenecimiento del conjunto de establecimientos con las numerosos empresas creadas en los últimos años.

\section{ZONA DE MATILDE HERNÁNDEZ-PEDRO DÍEZ}

Situada en el extremo meridional del barrio de San Isidro, esta pequeña zona de algo más de $15 \mathrm{Ha}$. acapara más del $85 \%$ del empleo de ese 
barrio y algo más de la tercera parte de todo Carabanchel. No obstante, también existen en ella, aunque en una mínima proporción, otros usos no fabriles y se pueden destacar los siguientes servicios: de carácter institucional (I.N.E.M., Comunidad de Madrid), concesionarios de coches, técnicos de automoción, compañías de seguros, talleres de reparaciones, servicios religiosos, e incluso algunas casas residuales de uso residencial.

La zona se caracteriza por su heterogeneidad edificatoria, y tiene como peculiaridad la industria en vertical, es decir los edificios industriales (algunos hasta con 9 establecimientos por planta), por lo que su densidad industrial es muy elevada.Salvo algunas excepciones de empresas con parcela, edificios enteros, etc., la mayoria de los establecimientos se reducen a una nave, donde se desarrolla el proceso productivo y que además tiene físicamente integradas, en un pequeño despacho, las tareas de gestión y administración. En algunas empresas de cierto tamaño la oficina puede ocupar hasta una planta del edificio. Las dimensiones de las naves que ocupan son muy variables, la media aritmética de las empresas encuestadas está en más de $600 \mathrm{~m}^{2}$, pero es poco fiable ya que los casos se distrubuyen en un amplio abanico y van, desde los 110 hasta los $5.000 \mathrm{~m}^{2}$. Obviando estos valores extremos, la media quedaría en $414 \mathrm{~m}^{2}$, que es bastante más representativa.

Los dos tercios de las empresas alli instaladas tienen los establecimientos en régimen de alquiler y el resto de las naves suele pertenecer, a antiguas empresas que adquirieron la propiedad en otra época, o a poderosas empresas muy interesadas en permanecer en la zona.

En cuanto a la relocalizaciones, casi la mitad de las empresas proceden de otras zonas del municipio (Centro, Tetuán, etc.) o del propio distrito (son frecuentes dentro de la zona) y generalmente se fueron de su anterior emplazamiento por necesidades de ampliación (la mayoría de los relocalizados se instalaron antes de 1975). Del resto de establecimientos un tercio de los empresarios encuestados vive en el distrito (normalmente suelen ser empresas de una cierta antigüedad).

Existe una abundante mortalidad infantil empresarial en la zona, pero el volumen de establecimientos no disminuye por la incesante creación de tejido industrial. Haciendo una tipología de antiguas modernas y recientes en función de la fecha de creación, se observa que algo más de la quinta parte son anteriores a 1975, casi la mitad se crearon en el período de crisis (1976 a 1985) y las restantes son posteriores a 1986. Conviene insistir en la persistencia de gran parte de las empresas desde épocas anteriores a la crisis.

Más de los dos tercios de las empresas encuestadas fabrican bienes o productos finales, la quinta parte semielaborados y el resto de ambos 
tipos. Los flujos de mercancías que generan tienen un alcance muy diverso, las producciones van dirigidas mayoritariamente hacia el área metropolitana de Madrid, sin embargo bastantes empresas, más de un tercio, destinan al mercado nacional una parte importante de su producción y solo la décima parte traspasa las fronteras, normalmente a países de la C.E.E. Por otra parte, siguiendo con aspectos productivos, la mayoria adquieren las materias primas en el mercado nacional (suelen comprar a mayoristas y almacenes de la Comunidad de Madrid), aunque en algunos casos necesitan recurrir a los proveedores extranjeros en función de sus determinadas peculiaridades.

Haciendo una brevísima sintesis de las actividades, es necesario resaltar que este interesante espacio cuenta con un amplio abanico productivo, estando representados a un nivel de desagregación de tres dígitos del C.N.A.E. casi 50 subsectores. No obstante, se evidencia una fuerte especialización en papel, imprentas y edición, con casi la mitad de las empresas, y una proporción algo menor del empleo de la zona. También tiene gran importancia la confección, actividad desarrollada por pocas empresas, pero que ocupan bastantes trabajadores.

\section{FACTORES DE LOCALIZACIÓN}

Este apartado se va a confeccionar en base a la encuesta y a la observación directa durante los recorridos efectuados por el barrio. Dentro de él se van a considerar por separado las ventajas y los inconvenientes que han estimado los responsables de las empresas.

\subsection{Ventajas de la localización}

Esta pregunta ha sido contestada por casi todas las empresas aunque los interlocutores no han efectuado la ponderación que se les pedía. Lógicamente, algunos han señalado diversas causas responsables de su actual implantación en la zona.

El principal factor de localización según la encuesta es la cercania a proveedores y clientes que aparece en algo más del $60 \%$ de los cuestionarios. Otros señalan también: las buenas condiciones para acceder a las naves $(45 \%)$; el precio barato, con la matización "de entonces" $(42 \%)$; Buena imagen, curiosamente, las imprentas señalaban que para su actividad era de las zonas más atractivas de Madrid por su peculiar forma de trabajo, en el que más adelante se profundizará al tratar los di- 
ferentes sectores (37\%); buena comunicación de autobús, metro, etc. $(28 \%)$; zona ya conocida, dado que algunas empresas provienen de la misma zona (21\%); Sitio céntrico y proximidad al domicilio del empresario $(14 \%)$.

En definitiva, se podría resumir, dado que algunas respuestas son reiterativas, señalando que la ubicación dentro del municipio de Madrid ha sido el factor que más ha influido (en función de las actividades de las empresas encuestadas) en la actual localización de los establecimientos en el barrio.

\subsection{Inconvenientes de la localización}

Dentro de los principales inconvenientes que sufren las empresas por su localización en el barrio destacan: como principal molestia el problema de aparcamiento ya que aparece en más del $80 \%$ de las encuestas; el difícil acceso a proveedores y clientes también tiene preocupados al $55 \%$ de los interlocutores. En realidad ambos son consecuencias de la urbanización a saltos, sobre antiguas parcelas rurales del barrio, y que en la zona de Matilde Hernández ha determinado una trama edificatoria urbana muy irregular, con la mayoria de las calles muy estrechas y poco adecuadas para el acceso de grandes vehículos. Todas las empresas situadas en $\mathrm{Ni}$ colás Morales y alrededores han señalado estos problemas (con trazado viario cuasi-árabe) y, por el contrario, no lo hacen las situadas en la Avda. Pedro Díez o en la calle Algorta. Por otro lado, según las empresas la ubicación de edificios institucionales agrava aún más la situación, «la gente viene a sellar la tarjeta del INEM en coche, cuando todos viven cerca", los que viene a hacer cursos a la Comunidad de Madrid. A todo ello, se le añaden los abundantes talleres de reparación «que dejan los automóviles fuera ocupando sitio".

Además de los dos citados problemas, también aparecen la escasez de casas de comidas e incluso los elevados precios de alquileres. Puede sorprender que una misma variable aparezca como factor de localización y como inconveniente, pero lógicamente su valoración está en función de la casuística del sector de actividad, de la fecha de comienzo del alquiler y de la solvencia económica de la empresa. Otros empresarios cuestionan problemas técnicos en relación con su actividad que se refieren más al edificio que ocupan que a la zona en si. Dentro de ellos deben destacarse por haber sido mencionados por varias empresas la industria en altura, pues al tener separadas las naves en pisos sufren los problemas que ocasiona el continuo uso del montacargas y preferirian un establecimiento de 
una sola planta. Además de los problemas anteriores, un 18\% del empresariado piensa que la localización de su establecimiento no tiene ningún tipo de inconvenientes.

\section{PERPECTIVAS DE FUTURO DEL TEJIDO FABRIL DE SAN ISIDRO}

Las mayores transformaciones se están dando en la zona de Matilde Hernández-Pedro Díez, y se producen intramuros, no se ven desde el exterior porque suelen afectar a los procesos productivos y están al margen de la morfología edificatoria. Dentro de este área hay un importante trasiego de empresas que van cambiando su localización de unos edificios a otros en función de sus necesidades espaciales y de su poder adquisitivo.

No obstante, también se puede apreciar el dinamismo de la zona desde fuera y si se pasea por ella, se puede comprobar la existencia de vaciados industriales, demoliciones en curso de naves 0 , por el contrario, edificios industriales en construcción, o que están en venta o alquiler, o a punto de ser estrenados. Se está dando un cambio morfológico, pero al contrario que en otras zonas (véase ONDATEGUI, J.C. 1993) el proceso de terciarización fabril es aquí incipiente, y en los edificios industriales (que están adosados y bajo la Ordenanza 9 del P.G.O.U. de 1985) suelen estar prácticamente ocupados por actividades fabriles. Es decir, que por las encuestas pasadas a las empresas no parece que exista un marcado cambio funcional.

Según los datos del directorio y en virtud de la información de la encuesta, parece más que probable que en el barrio de San Isidro aumente aún más la polarización del espacio fabril en favor de la zona legalmente regulada para tal uso. En ella parece que tiende a aumentar el número de establecimientos de imprenta por la alta consideración que la zona merece a los empresarios para esta actividad.

A pesar de la reducción del número de establecimientos (tanto en este área como en el resto del barrio), en los bordes, y confundida con el uso residencial, hay una pequeña industria dedicada, sobre todo, a Madera, Textil y pequeños Transformados del metal, que llega hasta la calle Irlanda y que ofrece una enorme resistencia al abandono de su actividad.

En definitiva, parece ser que en un futuro próximo se deben concentrar aun más, desde el punto de vista espacial, las actividades fabriles del distrito en el Barrio de San Isidro. 
ESTRUCTURA SECTORIAL DEL BARRIO DE COMILLAS EN 1992

\begin{tabular}{|c|c|c|c|c|c|c|}
\hline \multirow{2}{*}{ SECTORES } & \multicolumn{2}{|c|}{ ESTAB. } & \multicolumn{2}{|c|}{ EMPLEO } & \multirow{2}{*}{$\begin{array}{l}\text { TAMAÑO } \\
\text { EMP/EST. }\end{array}$} & \multirow{2}{*}{$\begin{array}{c}\text { COEF. ESP } \\
\text { DISTRITO } \\
\text { (EMPLEO) }\end{array}$} \\
\hline & № & $\%$ & No & $\%$ & & \\
\hline Metálicas básicas & 1 & 1,0 & 6 & 1,0 & 6,0 & 1,7 \\
\hline I. no metál.(vidrio) & 3 & 2,7 & 9 & 1,5 & 3,0 & 0,6 \\
\hline Industria química & 2 & 1,8 & 27 & 4,7 & 13,5 & 3,4 \\
\hline Const. metálicas & 9 & 8,1 & 27 & 4,7 & 3,0 & 0,9 \\
\hline Artículos metálicos & 5 & 4,5 & 21 & 3,6 & 4,3 & 0,8 \\
\hline Maquinaria industrial & 3 & 2,7 & 10 & 1,7 & 3,3 & 0,4 \\
\hline Mat.eltco y eltrónico & 14 & 12,6 & 56 & 9,6 & 4,0 & 1,3 \\
\hline Alimentación & 9 & 8,1 & 30 & 5,1 & 3,3 & 0,9 \\
\hline Textil, cuero, czdo. & 14 & 12,6 & 94 & 16,1 & 6,7 & 0,8 \\
\hline Papel, imprentas & 23 & 20,7 & 187 & 32,0 & 8,1 & 1,1 \\
\hline Madera y muebles & 22 & 19,8 & 83 & 14,2 & 3,8 & 1,7 \\
\hline Otras industrias & 6 & 5,4 & 34 & 5,8 & 5,7 & 1,0 \\
\hline Total Comillas & 111 & 100 & 584 & 100 & 5,3 & \\
\hline
\end{tabular}

Fuente: Directorio Industrial C. Madrid 1992 y elaboración propia.

ESTRUCTURA SECTORIAL DEL BARRIO DE OPAÑEL EN 1992

\begin{tabular}{|c|c|c|c|c|c|c|}
\hline \multirow{2}{*}{ SECTORES } & \multicolumn{2}{|c|}{ ESTAB. } & \multicolumn{2}{|c|}{ EMPLEO } & \multirow{2}{*}{$\begin{array}{l}\text { TAMAÑO } \\
\text { EMP/EST. }\end{array}$} & \multirow{2}{*}{$\begin{array}{l}\text { COEF. ESF } \\
\text { DISTRITO } \\
\text { (EMPLEO) }\end{array}$} \\
\hline & № & $\%$ & № & $\%$ & & \\
\hline Metálicas básicas & 2 & 1,1 & 9 & 0,9 & 4,5 & 1,5 \\
\hline I. no metál. & 6 & 3,4 & 27 & 2,6 & 4,5 & 1,0 \\
\hline Industria química & 4 & 2,3 & 21 & 2,0 & 5,3 & 1,4 \\
\hline Const. metálicas & 19 & 10,7 & 54 & 5,1 & 2,8 & 1,0 \\
\hline Artículos metálicos & 7 & 3,9 & 30 & 2,9 & 4,3 & 0,6 \\
\hline Maquinaria industrial & 9 & 5,1 & 102 & 9,7 & 11,3 & 2,5 \\
\hline Mat.eltco y eltrónico & 13 & 7,3 & 107 & 10,2 & 8,2 & 1,4 \\
\hline Alimentación & 25 & 14,1 & 127 & 12,1 & 5,1 & 2,0 \\
\hline Textil, cuero, czdo. & 24 & 13,6 & 196 & 18,7 & 8,2 & 0,9 \\
\hline Papel, imprentas & 28 & 15,8 & 191 & 18,2 & 6,8 & 0,6 \\
\hline Madera y muebles & 31 & 17,5 & 109 & 10,4 & 3,5 & 1,2 \\
\hline Otras industrias & 9 & 5,1 & 76 & 7,2 & 8,4 & 1,2 \\
\hline Total Opañel & 177 & 100 & 1.049 & 100 & 5,9 & \\
\hline
\end{tabular}

Fuente: Directorio Industrial C. Madrid 1992 y elaboración propia. 
Crisis y reestructuración de los tejidos fabriles en espacios intraurbanos...

ESTRUCTURA SECTORIAL DEL BARRIO DE VISTA ALEGRE EN 1992

\begin{tabular}{|c|c|c|c|c|c|c|}
\hline \multirow{2}{*}{ SECTORES } & \multicolumn{2}{|c|}{ ESTAB. } & \multicolumn{2}{|c|}{ EMPLEO } & \multirow{2}{*}{$\begin{array}{l}\text { TAMAÑO } \\
\text { EMPIEST. }\end{array}$} & \multirow{2}{*}{$\begin{array}{l}\text { COEF. ESP } \\
\text { OISTRITO } \\
\text { (EMPLEO) }\end{array}$} \\
\hline & № & $\%$ & № & $\%$ & & \\
\hline I. no metál. & 5 & 2,5 & 11 & 1,2 & 2,2 & 0,5 \\
\hline Industria química & 2 & 1,0 & 4 & 0,5 & 2,0 & 0,4 \\
\hline Const. metálicas & 21 & 10,3 & 55 & 6,2 & 2,6 & 1,2 \\
\hline Artículos metálicos & 8 & 3,9 & 27 & 3,0 & 3,4 & 0,6 \\
\hline Maquinaria industrial & 8 & 3,9 & 55 & 6,2 & 6,9 & 1,6 \\
\hline Mat.eltco y eltrónico & 18 & 8,8 & 85 & 9,6 & 4,7 & 1,3 \\
\hline Material transporte & 1 & 0,5 & 2 & 0,2 & 2,0 & 0,1 \\
\hline Alimentación & 21 & 10,3 & 107 & 12,1 & 5,1 & 2,0 \\
\hline Textil, cuero, czdo. & 39 & 19,1 & 279 & 31,5 & 7,2 & 1,5 \\
\hline Papel, imprentas & 29 & 14,2 & 70 & 7,9 & 2,4 & 0,3 \\
\hline Madera y muebles & 42 & 20,6 & 135 & 15,2 & 3,2 & 1,8 \\
\hline Otras industrias & 10 & 4,9 & 57 & 6,4 & 8,6 & 1,1 \\
\hline Total Vista Alegre & 204 & 100 & 887 & 100 & 4,3 & \\
\hline
\end{tabular}

Fuente: Directorio Industrial C. Madrid 1992 y elaboración propia.

ESTRUCTURA SECTORIAL DEL BARRIO DE VISTA ALEGRE EN 1992

\begin{tabular}{|c|c|c|c|c|c|c|}
\hline \multirow{2}{*}{ SECTORES } & \multicolumn{2}{|c|}{ ESTAB. } & \multicolumn{2}{|c|}{ EMPLEO } & \multirow{2}{*}{$\begin{array}{l}\text { TAMANNO } \\
\text { EMP/EST. }\end{array}$} & \multirow{2}{*}{$\begin{array}{l}\text { COEF. ESP } \\
\text { DISTRITO } \\
\text { (EMPLEO) }\end{array}$} \\
\hline & № & $\%$ & № & $\%$ & & \\
\hline Ind. no metálicas & 5 & 3,9 & 27 & 3,8 & 2,1 & 1,5 \\
\hline Const. metálicas & 16 & 12,3 & 38 & 5,3 & 2,4 & 1,1 \\
\hline Artículos metálicos & 6 & 4,6 & 7 & 1,0 & 1,1 & 0,2 \\
\hline Maquinaria industrial & 2 & 1,5 & 14 & 2,0 & 7,0 & 0,5 \\
\hline Mat.eltco y eltrónico & 6 & 4,6 & 89 & 12,6 & 14,8 & 1,7 \\
\hline Alimentación & 9 & 6,9 & 59 & 8,3 & 6,5 & 1,4 \\
\hline Textil, cuero, czdo. & 23 & 17,7 & 238 & 33,6 & 10,3 & 1,6 \\
\hline Papel, imprentas & 11 & 8,5 & 40 & 5,6 & 3,6 & 0,2 \\
\hline Madera y muebles & 42 & 32,3 & 108 & 15,2 & 2,6 & 1,8 \\
\hline Otras industrias & 10 & 7,7 & 89 & 12,6 & 8,9 & 2,1 \\
\hline Total Puerta Bonita & 130 & 100 & 709 & 100 & 5,5 & \\
\hline
\end{tabular}

Fuente: Directorio Industrial C. Madrid 1992 y elaboración propia. 
ESTRUCTURA SECTORIAL DEL BARRIO DE BUENAVISTA

\begin{tabular}{|c|c|c|c|c|c|c|}
\hline \multirow{2}{*}{ SECTORES } & \multicolumn{2}{|c|}{ ESTAB. } & \multicolumn{2}{|c|}{ EMPLEO } & \multirow{2}{*}{$\begin{array}{l}\text { TAMAÑO } \\
\text { EMP/EST. }\end{array}$} & \multirow{2}{*}{$\begin{array}{l}\text { COEF. ESP } \\
\text { DISTRITO } \\
\text { (EMPLEO) }\end{array}$} \\
\hline & $\mathrm{N}^{\mathrm{O}}$ & $\%$ & № & $\%$ & & \\
\hline I. no metál. & 3 & 3,0 & 6 & 0,7 & 2,0 & 0,3 \\
\hline Industria química & 1 & 1,0 & 3 & 0,4 & 3,0 & 0,3 \\
\hline Const. metálicas & 12 & 12,1 & 45 & 5,5 & 3,8 & 1,1 \\
\hline Artículos metálicos & 8 & 8,1 & 172 & 21,0 & 21,5 & 4,5 \\
\hline Maquinaria industrial & 1 & 1,0 & 1 & 0,1 & 1,0 & 0,0 \\
\hline Mat.eltco y eltrónico & 7 & 7,1 & 33 & 4,0 & 4,7 & 0,5 \\
\hline Material transporte & 1 & 1,0 & 4 & 0,5 & 4,0 & 0,3 \\
\hline Alimentación & 5 & 5,1 & 19 & 2,3 & 3,8 & 0,4 \\
\hline Textil, cuero, czdo. & 22 & 22,2 & 86 & 10,5 & 3,9 & 0,5 \\
\hline Papel, imprentas & 10 & 10,1 & 340 & 41,5 & 34,0 & 1,4 \\
\hline Madera y muebles & 26 & 26,3 & 97 & 11,9 & 3,7 & 1,4 \\
\hline Otras industrias & 3 & 3,0 & 13 & 1,6 & 4,3 & 0,3 \\
\hline Total Buenavista & 99 & 100 & 819 & 100 & 8,3 & \\
\hline
\end{tabular}

Fuente: Directorio Industrial C. Madrid 1992 y elaboración propia.

ESTRUCTURA SECTORIAL DEL BARRIO DE ABRANTES EN 1992

\begin{tabular}{|c|c|c|c|c|c|c|}
\hline \multirow{2}{*}{ SECTORES } & \multicolumn{2}{|c|}{ ESTAB. } & \multicolumn{2}{|c|}{ EMPLEO } & \multirow{2}{*}{$\begin{array}{l}\text { TAMAÑO } \\
\text { EMP/EST. }\end{array}$} & \multirow{2}{*}{$\begin{array}{c}\text { COEF. ESP. } \\
\text { DISTRITO } \\
\text { (EMPLEO) }\end{array}$} \\
\hline & № & $\%$ & № & $\%$ & & \\
\hline I. no metál. & 5 & 7,7 & 19 & 5,4 & 3,8 & 2,1 \\
\hline Const. metálicas & 6 & 9,3 & 24 & 6,8 & 4,0 & 1,4 \\
\hline Artículos metálicos & 1 & 1,5 & 1 & 0,3 & 1,0 & 0,1 \\
\hline Maquinaria industrial & 1 & 1,5 & 8 & 2,2 & 8,0 & 0,6 \\
\hline Mat.eltco y eltrónico & 1 & 1,5 & 2 & 0,5 & 2,0 & 0,1 \\
\hline Alimentación & 10 & 15,4 & 82 & 23,1 & 8,2 & 3,9 \\
\hline Textil, cuero, czdo. & 10 & 15,4 & 132 & 37,2 & 13,2 & 1,8 \\
\hline Papel, imprentas & 10 & 15,4 & 45 & 12,7 & 4,5 & 0,4 \\
\hline Madera y muebles & 17 & 26,2 & 35 & 9,8 & 2,1 & 1,2 \\
\hline Otras industrias & 4 & 6,1 & 7 & 2,0 & 1,8 & 0,3 \\
\hline Total Abrantes & 65 & 100 & 355 & 100 & 8,3 & \\
\hline
\end{tabular}

Fuente: Directorio Industrial C. Madrid 1992 y elaboración propia. 


\section{DISTRITOS DE MADRID}

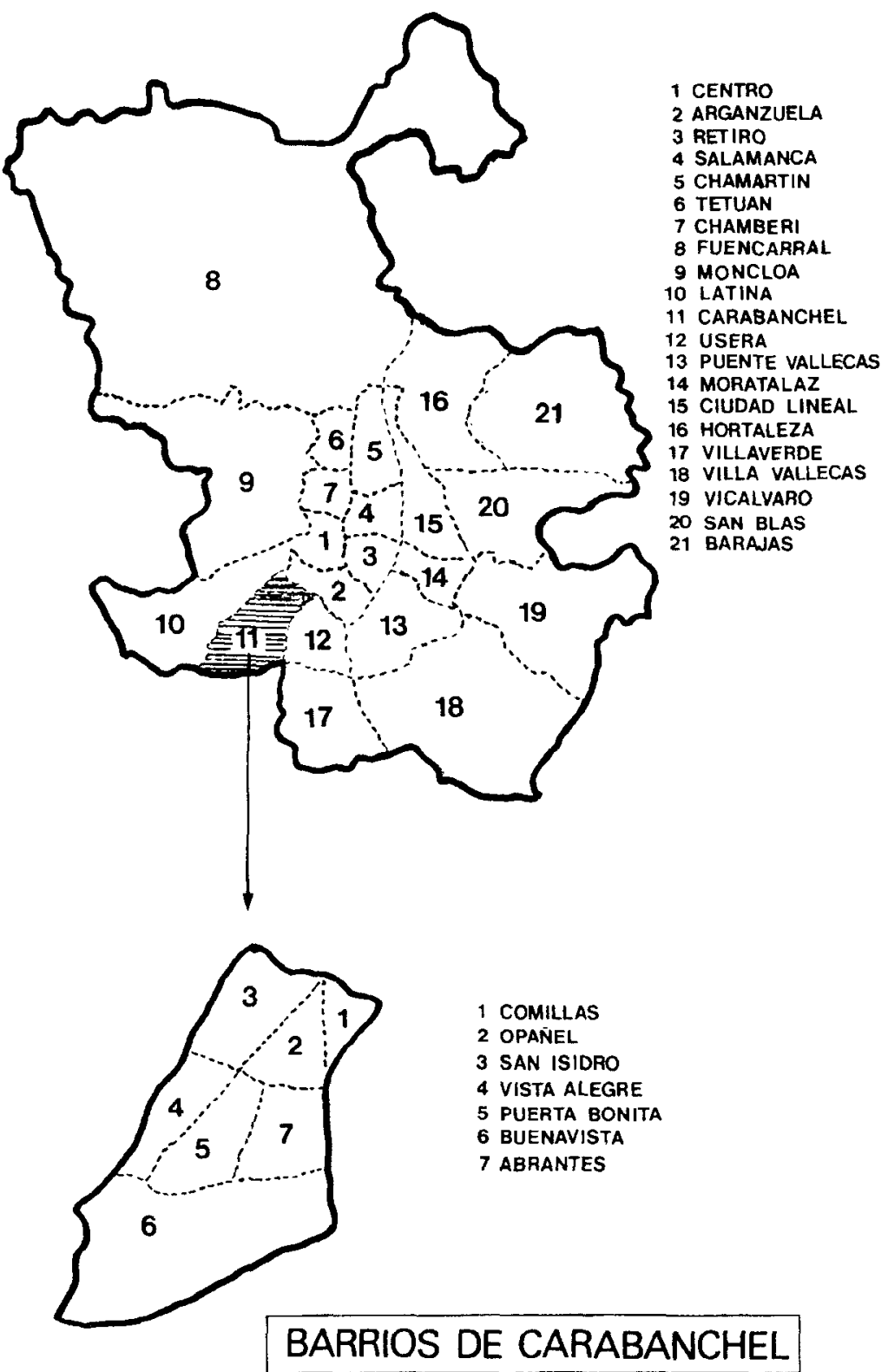




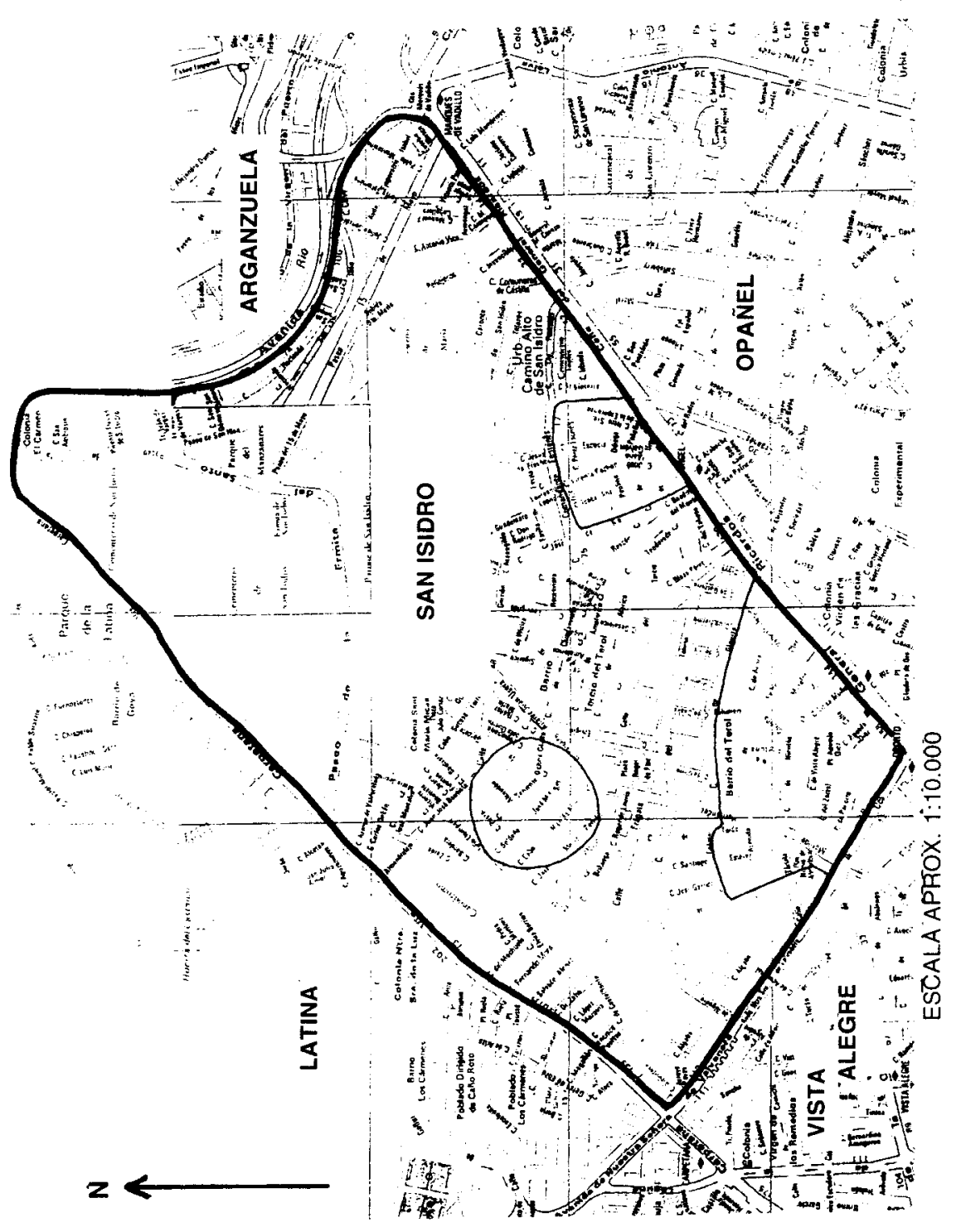




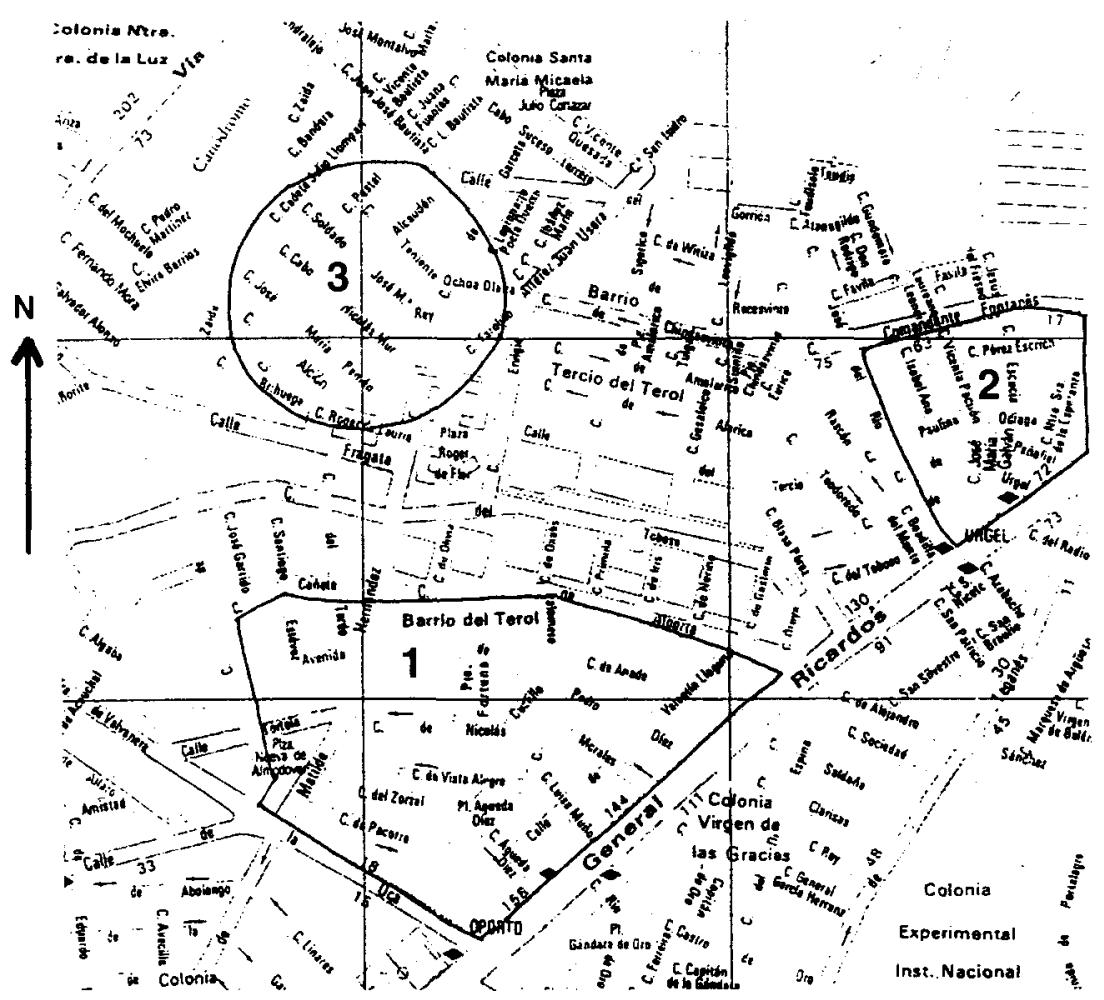

ESCALA APROX. 1:8.500

1. Zona de Matilde Hernández de industria concentrada (según el P.G.O.U. 9a).

2. Zona de industria dispersa con cierta concentración en Paulina Odiaga e Isabel Ana.

3. Zona de industria dispersa con cierta presencia en Soldado José María Rey, Cabo Nicolás Mur y Teniente Ochoa Olalla. 
BIBLIOGRAFIA

ÁlVAREZ, J.M. y OzCÁRIZ, M. (1989). “La reestructuración de la economía madrileña". Documento de trabajo $n^{\circ} 18$. Ayuntamiento de Madrid.

Ayuntamiento de MadRid (1985). «Plan General de Ordenación Urbana de Madrid". Normas Urbanísticas. Tomo 1. Madrid. Oficina Municipal del Plan.

CAmpos, G. (1985). "Metrópolis policéntricas y desafío tecnológico". en AA. VV. Metrópolis, territorio y crisis. Asamblea de Madrid, pp. 21-36.

Caravaca, I. y MÉndez, R. (1993). «Procesos de rrestructuración industrial en las aglomeraciones metropolitanas españolas». Madrid. ITUR (M.O.P.T).

CARRERA, M ${ }^{a}$ C. (1991). "La industria madrileña. Crisis, crecimiento y reorganización del espacio productivo", en Méndez R. coord. Reestructuración industrial en los espacios urbanos. Grupo Geografía Industrial (A.G.E.). pp. 69-82.

CARTER, H. (1983). «El estudio de la Geografía Urbana». Madrid. I.E.A.L. $578 \mathrm{pp}$.

CAstells, M. y otros (1990). "Estrategias de desarrollo metropolitano en las grandes ciudades españolas: articulación entre crecimiento económico y calidad de vida", en Borja, J. y otros edit. Las grandes ciudades en la década de los noventa. Madrid. Sistema. pp. 16-64.

Del Castillo, F. (1992). "Transformaciones recientes de espacios fabriles intraurbanos: el distrito de Carabanchel", en Méndez coord. Espacios industriales de Madrid. Grupo de Geografía Industrial. A.G.E. pp.

Ceccarelli, P. (1983). "Relocalización de las actividades productivas y planificación urbanística». Madrid. 
Celada, F., López Groh, F. y Parra, T. (1985). «Efectos espaciales de los procesos de reorganización del sistema productivo en Madrid». Madrid. Comunidad de Madrid. $488 \mathrm{pp}$.

Dézert, B., Verlaque, C. (1978). “L'espace industriel». Paris. Masson.

HaLL, P. (1985). "Capitales nacionales, ciudades internacionales y la nueva división del trabajo". Estudios Territoriales no 19, pp. 21-30.

MARcos, C. y otros (1988). "La economía madrileña en sus sectores». Consejería de Economía de la Comunidad de Madrid. Madrid.

MÉNDEZ, R. (1986). «Actividad industrial y estructura territorial en la región de Madrid". Madrid. Consejería de Trabajo, Industria y Comercio. Comunidad de Madrid. $335 \mathrm{pp}$.

MÉNDEZ, R. (1988). «Las actividades industriales». Madrid. Síntesis. 143 pp.

MÉNDEZ, R. (1991). «La reestructuración de la industria metropolitana y la nueva problemática urbanística", en Méndez, R. coord. Reestructuración industrial en los espacios urbanos. Madrid. Grupo de Geografia Industrial (A.G.E.). pp. 5-22.

Moreno, A. (1983). «Carabanchel. Recuperar el espacio vivido (Historia de Carabanchel)». Madrid. Junta Municipal de Distrito de Carabanchel. 244 pp.

Ondategui, J.C. (1993). «Terciarización industrial en el distrito de Fuencarral». Economía y Sociedad no 9. pp. 153-168.

Pecqueur, B. (1988). «Espacio de los territorios y nuevo modo de industrialización”. Estudios Territoriales n² 26. pp. 47-60.

Precedo, A. (1986). "La red urbana". Madrid. Síntesis.

Rodriguez AviAL, L. (Coord.) (1989). «Estudio sobre la situación actual y previsible evolución del sector industrial en el municipio de Madrid". Tomo I. (Información y análisis temporal). Madrid. Ayuntamiento de Madrid.

ROMERo, C. (1991). "Reestructuración económica y transformación de las áreas urbanas centrales: análisis de un caso concreto", en Méndez, R. coord. Reestructuración industrial de los espacios urbanos. Grupo de Geografia Industrial (A.G.E.). pp. 83-92.

ScotT, A.J. (1985). «Procesos de localización urbanización y desarrollo territorial: un ensayo exploratorio". Estudios Territoriales no 17, pp.17-40.

STÖHR, W. (1986). "Cambios estructurales en la industria y estrategias de desarrollo regional. Aproximaciones a un marco conceptual". Estudios Territoriales $n^{\circ} 20$, pp.132-141.

SUÁREZ VILLA, L. (1987). «Evolución metropolitana, cambio económico sectorial y distribución del tamaño de las ciudades". Estudios Territoriales $n^{\circ}$ 23, pp. 155-181. 